\title{
The Possible Role Serum Biochemical Analysis Can Play in Predicting an Infant's Risk of Retinopathy of Prematurity; Elevated Serum Magnesium
}

\author{
Muberra Akdogan', Mehmet Cem Sabaner'1, Yasemin Ustundag', \\ Mustafa Dogan', Ipek Guney Varal ${ }^{3}$ \\ ${ }^{1}$ Deparment of Opthalmology, Afyon Kocatepe University, Medical School, Afyonkarahisar, Turkey \\ ${ }^{2}$ Deparment of Clinical Biochemistry, HSU Bursa Yuksek Ihtisas Training and Research Hospital, Bursa, Turkey \\ ${ }^{3}$ Department of Newborn Clinic, HSU Bursa Yuksek Ihtisas Training and Research Hospital, Bursa, Turkey \\ Email: mbrakdogan@yahoo.com
}

How to cite this paper: Akdogan, M., Sabaner, M.C., Ustundag, Y., Dogan, M. and Varal, I.G. (2019) The Possible Role Serum Biochemical Analysis Can Play in Predicting an Infant's Risk of Retinopathy of Prematurity; Elevated Serum Magnesium. Journal of Biosciences and Medicines, 7, 71-82.

https://doi.org/10.4236/jbm.2019.71007

Received: November 21, 2018

Accepted: January 6, 2019

Published: January 9, 2019

Copyright $\odot 2019$ by author(s) and Scientific Research Publishing Inc. This work is licensed under the Creative Commons Attribution International License (CC BY 4.0).

http://creativecommons.org/licenses/by/4.0/

\section{(c) (i) Open Access}

\begin{abstract}
Purpose: We evaluated biochemical analysis results with the aim of discovering serum levels that have possible effects on the development of retinopathy of prematurity (ROP). Methods: A retrospective study was conducted between January 2017 and January 2018 on a total of 110 infants with 35 or less gestational weeks. The sample included 78 infants who had been diagnosed with different stages of ROP and 32 infants without ROP. Results from routine serum biochemical analyses, performed at birth and at one month after birth, were evaluated. The Independent Sample t-test and Mann-Whitney $\mathrm{U}$ test were performed to compare the data. Results: The infants with ROP were born at a mean of $28.0( \pm 2.1)$ weeks of gestation, weighing a mean of $1066( \pm 314) \mathrm{g}$, and the mean duration of stay in the incubator was $38.2( \pm 19)$ days. The infants without ROP were born at a mean of $29.6( \pm 2.6)$ weeks of gestation, weighing a mean of $1265( \pm 372)$ g. 59 infants (53.6\%) were females, and $51(46.4 \%)$ were males. Between infants with and without ROP, differences in the following levels were not statistically significant: glucose, blood urine nitrogen, creatinine, alanine aminotransferase, aspartate aminotransferase, albumin, total protein, direct bilirubin, indirect bilirubin, uric acid, and phosphorus. Serum magnesium $(\mathrm{Mg})$ levels at birth in infants with ROP were significantly higher than infants without ROP $(p=0.014)$. Conclusions: Serum $\mathrm{Mg}$ levels at birth were found to be higher in infants with ROP than in those without ROP. The levels may be dependent on the mothers' treatment of $\mathrm{Mg}$ for different medical reasons.
\end{abstract}




\section{Keywords}

Retinopathy of Prematurity, Magnesium, Serum Biochemical Analysis, Intermittent Hypoxemia

\section{Introduction}

Retinopathy of prematurity (ROP) is one of the most important health problems confronting at-risk premature infants. In neonatal intensive care units, rapid advances in current technology have enabled survival in infants with very low birth weight (birth weight $<1500$ g) and extremely low birth weight (birth weight $<1000 \mathrm{~g}$ ). Decreased mortality has led to an increase in the morbidity of these infants [1].

This paper explores the differences between normal babies and premature babies and seeks to determine the possible causes of ROP. In studies conducted so far, the most critical risk factor for ROP was found to be retinal vascular immaturity determined by low gestational age (GA) and low birth weight [2] [3] [4] [5]. Other risk factors include oxygen toxicity, acidosis, intraventricular hemorrhage, patent ductus arteriosus, sepsis, hyperbilirubinemia, low Apgar score, mechanical ventilation, and blood transfusion [6] [7] [8]. However, other preventable factors are still being investigated.

By revealing the differences between normal and premature infants, the possible causes of ROP can be investigated. The first difference that must be explored is hypoglycemia. Hypoglycemia is a complex of symptoms that occur with absolute and relative reduction of blood glucose and is characterized by various clinical findings. It is common in premature infants [9] [10] [11].

Second, in approximately $90 \%$ of newborns, jaundice is observed [12]. The duration and severity of jaundice are due to factors such as race, nutrition, gestational week, familial factors, maternal or intrauterine diseases, and medications. Third, the relationship between oxidative stress and hepatocellular damage in preterm infants was discussed in a study by Weinberger et al. [13]. In their study, the authors showed that in premature infants who received parenteral nutrition treatment, serum transaminase levels increased as a marker of hepatocellular damage, and transaminase levels increased in direct proportion to oxidant damage markers, independent of cholestasis. Similarly, Köşger et al. showed that liver function tests affected $6 \%$ of premature infants who received parenteral nutrition treatment [14].

It is important to ensure that potential diseases remain preventable and treatable by applying appropriate and timely screening and treatment programs. Considering prematurity to be a systemic disease, and investigating the etiopathogenesis of ROP systemically, can provide advantages in diagnosis and treatment.

Systemic serum biochemical analysis is extremely important for the follow-up 
of premature infants in neonatal intensive care units or during outpatient visits. In this study, we aimed to determine the systemic biochemical differences in premature infants with or without ROP and to determine the relationship between these differences and ROP.

\section{Material and Methods}

A sample of premature infants, 110 in total all with 35 or less gestational weeks, were studied retrospectively. The sample included 78 infants diagnosed with different stages of ROP and 32 infants without ROP. All of the infants were referred from our hospital's neonatal intensive care unit to our clinic for screening and treatment between January 2017 and January 2018. Results from routine serum biochemical analyses, performed at birth and at one month after birth, were evaluated. Infants that had undergone blood transfusion, had sepsis or were diagnosed with necrotising enterocolitis were excluded from the study. Additional exclusion criteria included gestational age greater than 35 weeks, birth weight greater than $2800 \mathrm{~g}$, and family history of refraction errors. This study was approved by ethics committee for the Bursa Yuksek Ihtisas Training and Research Hospital Health Science University in Bursa, Turkey. The principles of the Declaration of Helsinki were followed.

\subsection{ROP Examination}

Five minutes before examination, the pupils of the infants were dilated by instilling 3 drops of $2.5 \%$ phenylephrine (Mydfrin, Alcon, USA) and $0.5 \%$ tropicamide (Tropamid, Bilim İlaç, Turkey) topical eye solution. After appropriate pupillary dilatation, topical anesthesia was applied with the instillation of proparacaine hydrochloride (Alcaine ${ }^{\circledR}$, Alcon, USA). The lids were opened using an eye speculum. Then, with an indirect ophthalmoscope and +28 dioptric lens, all retinal areas were examined with the aid of a scleral indenter, and fundus images were recorded into the Archimedes VGA imaging system (Pronova, Ankara, Turkey). All examinations were performed by a single physician (MA).

ROP was detected based on criteria from the "Early Treatment in Retinopathy of Prematurity" (ETROP) study and the "International Classification of Retinopathy of Prematurity" (ICROP) publication; severity of retinopathy between avascular areas, settlement (zone), amount of involvement (clocks) and peripapillary vasculature examination findings by indicating the presence of anomaly (plus), it was noted [15] [16] [17] [18] [19]. Infants were treated according to the criteria of the ETROP and "Bevacizumab Eliminates the Angiogenic Threat of Retinopathy of Prematurity” (BEAT-ROP) study [18] [19] [20] [21].

\subsection{Sample Collection}

All blood samples from the 110 premature infants in the study were collected with an injector at least $2 \mathrm{cc}$ without hemolysis; samples were obtained at birth 
and one month after birth for routine systemic biochemical analysis. The serum separator tube (SST) cap was opened to avoid hemolysis, and the blood sample was transferred to the tube with the direct injector without using the needle tip. The SSTs were delivered to the biochemistry laboratory without any shaking. The SSTs were centrifuged after coagulation, which was created by allowing the collected samples to stand for at least 10 minutes. All SSTs were centrifuged at $4000 \mathrm{rpm}$ for 10 minutes by centrifuge device (Nüve, NF $1200 \mathrm{R}$, Ankara, Turkey).

\subsection{Biochemical Study and Analysis}

All biochemical serum analyzes were performed on the same device (Architect C16000, Abbott Diagnostics, Abbott Park, IL, USA) after necessary routine control and calibration check. The levels of glucose $(\mathrm{mg} / \mathrm{dl})$, blood urine nitrogen (BUN) (mg/dl), creatinine (mg/dl), aminotransferase (ALT) enzyme activity $(\mathrm{U} / \mathrm{L})$, aspartate aminotransferase (AST) $(\mathrm{U} / \mathrm{L})$, total albumin $(\mathrm{mg} / \mathrm{dl})$, total protein $(\mathrm{mg} / \mathrm{dl})$, direct bilirubin $(\mathrm{mg} / \mathrm{dl})$, indirect bilirubin $(\mathrm{mg} / \mathrm{dl})$, magnesium $(\mathrm{Mg})(\mathrm{mg} / \mathrm{dl})$ and phosphorus $(\mathrm{P})(\mathrm{mg} / \mathrm{dl})$ were determined by spectrophotometric analysis using commercially available assay kits (Abbott Diagnostics, Abbott Park, IL, USA) with an Architect C16000 autoanalyzer (Abbott Diagnostics, Abbott Park, IL, USA).

\subsection{Statistical Analysis}

Statistical software package SPSS 22.0 software for Windows (IBM Inc., Chicago, Illinois, USA) was used for the analysis of the data. Independent Sample t-test and Mann-Whitney $U$ test were used to compare the data between infants with or without ROP. Descriptive statistics are expressed as the frequency and percentage for qualitative data and as the mean \pm standard deviation or median (range) for quantitative data with and without normal distribution, respectively. p-value $<0.05$ was considered statistically significant.

\section{Results}

One-hundred and ten premature infants were enrolled in the study. 78 (70.9\%) infants were diagnosed with ROP at various stages and they were born at a mean of $28.0( \pm 2.1)$ weeks of gestation, weighing a mean of $1066( \pm 314) \mathrm{g}$ and the mean duration of stay at the incubator was $38.2( \pm 19)$ days. The remaining 32 (29.1\%) infants didn't have ROP and they were born at a mean of $29.6( \pm 2.6)$ weeks of gestation, weighing a mean of $1265( \pm 372)$ g. Of the infants, $59(53.6 \%)$ were females and 51 (46.4\%) were males.

Infants with ROP were fed with 10 (12.8\%) breastfeeding, 18 (23.1\%) formula-feeding and 50 (64.1\%) both breastfeeding and formula-feeding. Infants without ROP were fed with 7 (21.9\%) breastfeeding, 3 (9.4\%) formula-feeding and $22(68.8 \%)$ both breastfeeding and formula-feeding.

In serum fasting glucose averages were $46.51 \pm 29.62 \mathrm{mg} / \mathrm{dl}$ at birth, and 96.68 
$\pm 34.50 \mathrm{mg} / \mathrm{dl}$ at one month after birth in all premature infants (Table 1). There was no difference between with or without ROP in serum glucose parameters at birth or one month after birth (Table 2).

In serum kidney parameters' averages were BUN $7.47 \pm 4.2 \mathrm{mg} / \mathrm{dl}$, creatinine $0.69 \pm 0.14 \mathrm{mg} / \mathrm{dl}$, uric acid $5.4 \pm 1.8 \mathrm{mg} / \mathrm{dl}$ at birth, and BUN $5.24 \pm 1.97 \mathrm{mg} / \mathrm{dl}$, creatinine $0.51 \pm 0.07 \mathrm{mg} / \mathrm{dl}$, uric acid $2.1 \pm 1.1 \mathrm{mg} / \mathrm{dl}$ at one month after birth in all premature infants. There was no difference between with or without ROP in serum kidney parameters at birth or one month after birth.

In serum liver parameters' averages were AST $42.5 \pm 17.75$ U/L, ALT $5.0 \pm 2.0$ $\mathrm{U} / \mathrm{L}$, direct bilirubin $0.63 \pm 0.15 \mathrm{mg} / \mathrm{dl}$, indirect bilirubin $2.18 \pm 0.80 \mathrm{mg} / \mathrm{dl}$, total albumin $2.9 \pm 0.5 \mathrm{mg} / \mathrm{dl}$, total protein $4.0 \pm 0.6 \mathrm{mg} / \mathrm{dl}$ at birth, and AST $23.5 \pm$ $9.0 \mathrm{U} / \mathrm{L}$, ALT $13.94 \pm 11.2 \mathrm{U} / \mathrm{L}$, direct bilirubin $0.38 \pm 0.27 \mathrm{mg} / \mathrm{dl}$, indirect bilirubin $0.83 \pm 0.63 \mathrm{mg} / \mathrm{dl}$, total albumin $2.9 \pm 0.38 \mathrm{mg} / \mathrm{dl}$, total protein $4.2 \pm 0.7$ $\mathrm{mg} / \mathrm{dl}$ at one month after birth in all premature infants. There was no difference between with or without ROP in serum liver parameters at birth or one month after birth.

In serum electrolytes parameters' averages were P $5.69 \pm 1.37 \mathrm{mg} / \mathrm{dl}, \mathrm{Mg} 2.24$ $\pm 0.7 \mathrm{mg} / \mathrm{dl}$ at birth, and P $5.64 \pm 0.91 \mathrm{mg} / \mathrm{dl}, \mathrm{Mg} 1.91 \pm 0.34 \mathrm{mg} / \mathrm{dl}$ at one month after birth in all premature infants. There was no difference between with or without ROP in P parameter at birth or one month after birth. Although, the average of serum $\mathrm{Mg}$ level at birth in infants with ROP significantly higher than infants without ROP $(\mathrm{p}=0.014)$ (Table 2$)$.

Table 1. The results of biochemical parameters at birth and one month after birth in all premature infants.

\begin{tabular}{ccc}
\hline & At birth & At one month after birth \\
\hline Mean \pm standard deviation & & \\
\hline Glucose (mg/dl) & $46.51 \pm 29.62$ & $96.68 \pm 34.50$ \\
BUN (mg/dl) & $7.47 \pm 4.2$ & $5.24 \pm 1.97$ \\
Creatinine (mg/dl) & $0.69 \pm 0.14$ & $0.51 \pm 0.07$ \\
AST (U/L) & $42.5 \pm 17.75$ & $23.5 \pm 9.0$ \\
ALT (U/L) & $5.0 \pm 2.0$ & $13.94 \pm 11.2$ \\
Direct bilirubin (mg/dl) & $0.63 \pm 0.15$ & $0.38 \pm 0.27$ \\
Indirect bilirubin (mg/dl) & $2.18 \pm 0.80$ & $0.83 \pm 0.63$ \\
Total protein (mg/dl) & $4.0 \pm 0.6$ & $4.2 \pm 0.7$ \\
Total albumin (mg/dl) & $2.9 \pm 0.5$ & $2.9 \pm 0.38$ \\
Uric acid (mg/dl) & $5.4 \pm 1.8$ & $2.1 \pm 1.1$ \\
P (mg/dl) & $5.69 \pm 1.37$ & $5.64 \pm 0.91$ \\
Mg (mg/dl) & $2.24 \pm 0.7$ & $1.91 \pm 0.34$
\end{tabular}

BUN: Blood urine nitrogen, AST: Aspartate aminotransferase, ALT: Alanine aminotransferase, Mg: Magnesium and P: Phosphorus. 
Table 2. Comparison of the biochemical parameters' results at birth and one month after birth in premature infants with and without ROP.

\begin{tabular}{|c|c|c|c|}
\hline & With ROP & Without ROP & p value $e^{*}$ \\
\hline \multicolumn{4}{|c|}{ At Born (mean \pm standard deviation) } \\
\hline Glucose (mg/dl) & $45.17( \pm 30.1)$ & $49.95( \pm 28.79)$ & 0.424 \\
\hline BUN (mg/dl) & $9.95( \pm 5.0)$ & $9.79( \pm 5.9)$ & 0.747 \\
\hline Creatinine (mg/dl) & $0.71( \pm 0.17)$ & $0.69( \pm 0.17)$ & 0.507 \\
\hline $\operatorname{AST}(\mathrm{U} / \mathrm{L})$ & $54.2( \pm 37.4)$ & $58.8( \pm 63.2)$ & 0.603 \\
\hline $\operatorname{ALT}(\mathrm{U} / \mathrm{L})$ & $6.1( \pm 6.6)$ & $7.2( \pm 7.7)$ & 0.810 \\
\hline Direct bilirubin (mg/dl) & $0.64( \pm 0.18)$ & $0.57( \pm 0.18)$ & 0.116 \\
\hline Indirect bilirubin (mg/dl) & $2.18( \pm 0.81)$ & $2.09( \pm 0.83)$ & 0.536 \\
\hline Total protein (mg/dl) & $3.9( \pm 0.6)$ & $4.2( \pm 0.6)$ & $0.071^{+}$ \\
\hline Total albumin (mg/dl) & $2.8( \pm 0.4)$ & $3.0( \pm 0.4)$ & $0.115^{+}$ \\
\hline Uric acid (mg/dl) & $5.4( \pm 1.8)$ & $5.3( \pm 1.9)$ & 0.849 \\
\hline $\mathrm{Mg}(\mathrm{mg} / \mathrm{dl})$ & $2.3( \pm 0.78)$ & $2.0( \pm 0.34)$ & 0.014 \\
\hline $\mathrm{P}(\mathrm{mg} / \mathrm{dl})$ & $5.9( \pm 1.25)$ & $5.8( \pm 0.96)$ & $0.893^{+}$ \\
\hline \multicolumn{4}{|c|}{ At one month after birth (mean \pm standard deviation) } \\
\hline Glucose (mg/dl) & $96.36( \pm 35.19)$ & $97.80( \pm 33.15)$ & 0.940 \\
\hline BUN (mg/dl) & $8.28( \pm 7.1)$ & $8.01( \pm 4.4)$ & 0.629 \\
\hline Creatinine $(\mathrm{mg} / \mathrm{dl})$ & $0.51( \pm 0.11)$ & $0.48( \pm 0.08)$ & $0.313^{+}$ \\
\hline AST & $31.71( \pm 20.0)$ & $29.29( \pm 10.9)$ & 0.692 \\
\hline ALT & $14.01( \pm 12.66)$ & $13.77( \pm 6.0)$ & 0.591 \\
\hline Direct bilirubin (mg/dl) & $0.35( \pm 0.27)$ & $0.31( \pm 0.20)$ & 0.955 \\
\hline Indirect bilirubin (mg/dl) & $0.97( \pm 1.06)$ & $1.31( \pm 1.84)$ & 0.639 \\
\hline Total protein (mg/dl) & $4.1( \pm 0.7)$ & $4.6( \pm 0.7)$ & 0.096 \\
\hline Total albumin (mg/dl) & $2.9( \pm 0.3)$ & $3.1( \pm 0.3)$ & 0.108 \\
\hline Uric acid $(\mathrm{mg} / \mathrm{dl})$ & $2.1( \pm 0.9)$ & $2.4( \pm 1.7)$ & 0.930 \\
\hline $\mathrm{Mg}(\mathrm{mg} / \mathrm{dl})$ & $1.9( \pm 0.36)$ & $1.8( \pm 0.29)$ & 0.511 \\
\hline $\mathrm{P}(\mathrm{mg} / \mathrm{dl})$ & $5.6( \pm 1.13)$ & $5.8( \pm 0.72)$ & 0.688 \\
\hline
\end{tabular}

*: Mann-Whitney $\mathrm{U}$ test and Independent t-test $\left(^{+}\right)$results $\mathrm{p}<0.05$ were considered to be statistically significantly different and was indicated in bold. BUN: Blood urine nitrogen, AST: Aspartate aminotransferase, ALT: Alanine aminotransferase, Mg: Magnesium and P: Phosphorus.

\section{Discussion}

Minerals which are micronutrients in serum, if the major systemic disease was not detected in premature cases, it was found that infants could be associated with nutritional intake. Bauer et al. showed that serum phosphorus value was not different between extremely ( $<28$ weeks GA), severely ( 28 - 31 weeks GA), moderately (32 - 33 weeks GA) preterm infants and term infants [22]. In our study, although different nutrients were fed other than breastfeeding, no differ- 
ence was found in the value of phosphorus. Serum $\mathrm{Mg}$ level of the infant is generally higher than that of the mother. The factor that might contribute to high fetal serum magnesium levels is the ability of the placenta to active transport magnesium across to and hence concentrating magnesium in the fetus, resulting in increased serum magnesium levels compared with those in the maternal serum [23]. Besides that, the dose regimens, maternal serum magnesium levels, gestational age and birth weight, may influence the higher fetal serum magnesium levels. Various studies using high dose regimens of magnesium sulfate treatments were associated with increased mortality in the magnesium-exposed neonates, although it did not reach statistical significance [23] [24] [25] [26]. Mg has antioxidant properties, it is known that if magnesium deficiency is seen together with copper deficiency, to cause disorders in antioxidant enzyme activities. Mothers can be supplemented with $\mathrm{Mg}$ to prevent possible hypomagnesemia due to diabetes mellitus, pre-eclampsia diagnosis and mothers with low birth weight fetus. When the pathogenesis of ROP is examined, many of these conditions are present in these mothers. High levels of $\mathrm{Mg}$ inhibit Ca-linked reactions, such as muscle paralysis, dilatation of the arteries and failure of respiratory failure can be seen [27]. In our study, the average of serum $\mathrm{Mg}$ level at birth in infants with ROP significantly higher than infants without ROP. Although $\mathrm{Mg}$ has antioxidant properties and a decrease in neurological defects; there are studies showing that $\mathrm{Mg}$ levels at birth are higher in infants with ROP [23] [27] [28]. These results are also consistent with our study present result.

The incidence of hypoglycemia in premature infants up to 14\% [9] [10] [11]. Due to the presence of insufficient glycogen and fat in the depots, hypoglycemia is observed in the first 2 weeks of life in premature, especially in sick premature infants [10]. However, in our study, no difference was found between the birth and one month after birth in serum fasting glucose of the infants with and without ROP. Which may be explained by measures taken to prevent a possible hypoglycemia in the neonatal unit.

Preterm infants are more disadvantageous in hyperbilirubinemia status. Physiological jaundice (non-pathologic unconjugated hyperbilirubinemia) reaches its highest level in the first 3 days of life and returns to normal in a week without any lasting effect. In premature infants, this increase occurs in 5-7 days and returns to normal within 4 weeks [29] [30]. Therefore, the indications and applications of blood exchange and phototherapy are completely different from the term neonates [12]. Hyperbilirubinemia in preterm infants has been shown that it causes chore-athetoid cerebral palsy, high-frequency central neural hearing loss, palsy of vertical gaze, dental enamel hypoplasia [30]. Despite the previously reported conflicting clinical results, there was no complete association between serum bilirubin levels and ROP in prospective studies [31] [32] [33].

Elevations in AST and ALT levels due to hepatocellular and cholestatic injury can be seen in preterm infants [13] [34]. In our study, no difference was found between the birth and one month after birth in routine liver biochemical tests 
results of the infants with and without ROP. We attribute this to the fact that no infant has liver or cholestatic problems. Additionally, we attribute the fact that serum protein and serum albumin levels are not affected by the fact that babies are well fed due to breastfeeding and formula-feeding.

Major changing in renal function contribute to the patterns of serum BUN and creatinine change in preterm infants [35]. Postmortem histologic researches on kidney from preterm infants demonstrated that nephrogenesis continues after early third-trimester preterm birth, although with a higher number of structurally abnormal glomeruli compared with gestational week matched controls [35] [36] [37]. In our study, no difference was found between the birth and one month after birth in routine kidney biochemical tests results of the infants with and without ROP. We attribute this to the fact that whole preterm infants were normal kidney development and no infant has kidney or systemic nephrotoxic problems.

Various epidemiological and experimental evidence suggested that uric acid plays a role in the etiology of various retinal diseases [38] [39] [40]. Although, in our study, no difference was found between the birth and one month after birth in a routine uric acid test result of the infants with and without ROP.

The main limitations of this study are its retrospective design and small sample size. Thus, further studies with a larger number of infants with new biochemical measurements and longer follow-up period are needed to confirm or not these results.

\section{Conclusion}

In conclusion, this study showed that there is no significant difference between liver and renal function tests between infants with and without ROP. Although, serum $\mathrm{Mg}$ level at birth in infants with ROP was found significantly higher than without ROP. It may attribute that mothers of infants with ROP may be dependent on their treatment of $\mathrm{Mg}$ for different medical reasons (eclampsia etc.). Coordination of pediatricians and neonatologists is as important as ophthalmologists in the follow-up and rehabilitation of ROP. Pediatricians and neonatologists such as ophthalmologists should also be well known of retinal vascular development, ROP identification, frequency, pathophysiology, risk factors, screening programs and treatment principles.

\section{Funding}

No funding was received for this research.

\section{Declaration of Interest}

The authors report no conflict of interest. The authors alone are responsible for the content and writing of this article.

\section{Disclosure Statement}

All authors certify that they have no affiliations with or involvement in any or- 
ganization or entity with any financial interest or non-financial interest in the subject matter or materials discussed in this manuscript.

\section{Ethical Approval}

The study adhered to the tenets of the Declaration of HSU Bursa Yuksek Ihtisas Training and Research Hospital Ethics Committee of Clinical Research approved the study protocol.

\section{References}

[1] Yang, M.B. (2016) Retinopathy of Prematurity. In: Traboulsi, E. and Utz, V., Eds., Practical Management of Pediatric Ocular Disorders and Strabismus. A Case-Based Approach, 299-305. https://doi.org/10.1007/978-1-4939-2745-6_29

[2] Husain, S.M., Sinha, A.K., Bunce, C., Arora, P., Lopez, W., Mun, K.S., et al. (2013) Relationships between Maternal Ethnicity, Gestational Age, Birth Weight, Weight Gain, and Severe Retinopathy of Prematurity. Journal of Pediatrics, 163, 67-72. https://doi.org/10.1016/j.jpeds.2012.12.038

[3] Woo, S.J., Park, K.H., Ahn, J., Oh, K.J., Lee, S.Y., Jeong, E.H., et al. (2011) A Co-Twin Study of the Relative Effect of Birth Weight and Gestational Age on Retinopathy of Prematurity. Eye, 25, 1478-1483. https://doi.org/10.1038/eye.2011.208

[4] Esen, E., Erdem, E., Yar, K., Demircan, N. and Soylu, M. (2014) Results of Screening for Retinopathy of Prematurity: How the Ideal Screening Program Should Be? Türk Oftalmoloji Dergisi, 44, 42-46. http://cms.galenos.com.tr/FileIssue/6/132/article/42-46.pdf

[5] Bas, A.Y., Koc, E., Dilmen, U., Oguz, S.S., Ovali, F., Demirel, N., et al. (2015) Incidence and Severity of Retinopathy of Prematurity in Turkey. British Journal of Ophthalmology [Internet]. 99, 1311-1314.

http://bjo.bmj.com/content/99/10/1311.abstract https://doi.org/10.1136/bjophthalmol-2014-306286

[6] Hartnett, M.E. and Penn, J.S. (2012) Mechanisms and Management of Retinopathy of Prematurity. New England Journal of Medicine, 367, 2515-2526.

http://www.nejm.org/doi/abs/10.1056/NEJMra1208129 https://doi.org/10.1056/NEJMra1208129

[7] Chirico, G., Di Stefano, G., Romeo, M.G., Scuderi, A., Di Pietro, M., Pisano, F., et al. (1997) Italian Multicentre Study on Retinopathy of Prematurity. European Journal of Pediatrics, 156, 939-943. https://doi.org/10.1007/s004310050747

[8] Akdogan, M., Demirag, D., Varal, I., Cevik, S. and Ustundag, Y. (2018) Haemogram Parameters in the Development of Retinopathy of Prematurity. Open Journal of Ophthalmology, 8, 75-83. http://www.scirp.org/journal/ojoph https://doi.org/10.4236/ojoph.2018.82011

[9] Jain, A., Aggarwal, R., Jeeva Sankar, M., Agarwal, R., Deorari, A.K. and Paul, V.K. (2010) Hypoglycemia in the Newborn. Indian Journal of Pediatrics, 77, 1137-1142. https://doi.org/10.1007/s12098-010-0175-1

[10] Rozance, P.J. (2014) Update on Neonatal Hypoglycemia. Current Opinion in Endocrinology, Diabetes and Obesity, 21, 45-50. https://doi.org/10.1097/MED.0000000000000027

[11] Sharon, P., Melinda, B. and Donna, G. (2013) Breastfeeding the Preterm Infant. In: Patole, S., Ed., Nutrition for the Preterm Neonate: A Clinical Perspective, Springer, 
Dordrecht, 337-365. https://doi.org/10.1007/978-94-007-6812-3_17

[12] Ambalavanan, N. and Carlo, W.A. (2016) Jaundice and Hyperbilirubinemia in the Newborn. In: Behrman, R.E., Kliegman, R.M. and Jenson, H.B., Eds., Nelson Textbook of Pediatrics, Saunders, Philadelphia, 871.

[13] Weinberger, B., Watorek, K., Strauss, R., Witz, G., Hiatt, M. and Hegyi, T. (2002) Association of Lipid Peroxidation with Hepatocellular Injury in Preterm Infants. Critical Care, 6, 521-525. https://doi.org/10.1186/cc1547

[14] Köşger, P., Özer, E. and Helvac1, M. (2016) Preterm bebeklerde total parenteral beslenme ile ilişkili komplikasyonların sıklığı ve risk faktörleri. Journal of Pediatric Research, 3, 149-153. https://doi.org/10.4274/jpr.29591

[15] Drenser, K.A., Trese, M.T. and Capone, A. (2010) Aggressive Posterior Retinopathy of Prematurity. Retina, 30, S37-S40. https://doi.org/10.1097/IAE.0b013e3181cb6151

[16] Wilkinson, A.R., Haines, L., Head, K. and Fielder. A.R. (2008) UK Retinopathy of Prematurity Guideline. Early Human Development, 84, 71-74. https://doi.org/10.1016/j.earlhumdev.2007.12.004

[17] Shah, P.K. (2016) Retinopathy of Prematurity: Past, Present and Future. World Journal of Clinical Pediatrics, 5, 35-46. https://doi.org/10.5409/wjcp.v5.i1.35 http://www.wjgnet.com/2219-2808/full/v5/i1/35.htm

[18] Good, W.V., Hardy, R.J., Dobson, V., Palmer, E.A., Phelps, D.L., Quintos, M., et al. (2003) Revised Indications for the Treatment of Retinopathy of Prematurity: Results of the Early Treatment for Retinopathy of Prematurity Randomized Trial. Archives of Ophthalmology, 121, 1684-1696. https://doi.org/10.1001/archopht.121.12.1684 http://archopht.jamanetwork.com/article.aspx?doi=10.1001/archopht.121.12.1684

[19] The Early Treatment for Retinopathy of Prematurity Cooperative Group (2004) Final Results of the Early Treatment for Retinopathy of Prematurity (ETROP) Randomized Trial. Transactions of the American Ophthalmological Society, 102, 233-250, Discussion 248-250.

http://www.pubmedcentral.nih.gov/articlerender.fcgi?artid=1280104\&tool=pmcent $\underline{\text { rez\&rendertype }=\text { abstract }}$

[20] Tasman, W. (2011) Efficacy of Intravitreal Bevacizumab for Stage 3+ Retinopathy of Prematurity. The New England Journal of Medicine, 364, 603-615.

https://www.ncbi.nlm.nih.gov/pubmed/21323540

[21] Ha, M.-H. (2010) Bevacizumab Eliminates the Angiogenic Threat of Retinopathy of Prematurity (BEAT-ROP).

http://clinicaltrials.gov/ct2/show/NCT00622726?term=Bevacizumab+eliminates+th e+angiogenic + threat + of + retinopathy+of + prematurity+\%28BEAT-ROP\%29\&rank= $\underline{1}$

[22] Bauer, J. and Gerss, J. (2011) Longitudinal Analysis of Macronutrients and Minerals in Human Milk Produced by Mothers of Preterm Infants. Clinical Nutrition, 30, 215-220. https://doi.org/10.1016/j.clnu.2010.08.003

[23] Basu, S.K., Chickajajur, V., Lopez, V., Bhutada, A., Pagala, M. and Rastogi, S. (2012) Immediate Clinical Outcomes in Preterm Neonates Receiving Antenatal Magnesium for Neuroprotection. Journal of Perinatal Medicine, 40, 185-189. https://doi.org/10.1515/jpm.2011.094

[24] Grimes, D.A. and Nanda, K. (2006) Magnesium Sulfate Tocolysis: Time to Quit. Obstetrics and Gynecology, 108, 986-989. https://doi.org/10.1097/01.AOG.0000236445.18265.93

[25] Mittendorf, R., Covert, R., Boman, J., Khoshnood, B., Lee, K.S. and Siegler, M. 
(1997) Is Tocolytic Magnesium Sulphate Associated with Increased Total Paediatric Mortality? Lancet, 350, 1517-1518. https://doi.org/10.1016/S0140-6736(97)24047-X

[26] Rouse, D.J., Hirtz, D.G., Thom, E., Varner, M.W., Spong, C.Y., Mercer, B.M., et al. (2009) A Randomized, Controlled Trial of Magnesium Sulfate for the Prevention of Cerebral Palsy. Obstetrical and Gynecological Survey, 64, 15-17. https://doi.org/10.1097/01.ogx.0000340767.26768.9c

[27] Edwards, J.M., Edwards, L.E., Swamy, G.K. and Grotegut, C.A. (2018) Effect of Cord Blood Magnesium Level at Birth on Non-Neurologic Neonatal Outcomes. American Journal of Perinatology, 27. https://doi.org/10.1055/s-0038-1627097

[28] Caddell, J.L. (1995) Hypothesis: The Possible Role of Magnesium and Copper Deficiency in Retinopathy of Prematurity. Magnesium Research, 8, 261-270.

[29] Wallenstein, M.B. and Bhutani, V.K. (2013) Jaundice and Kernicterus in the Moderately Preterm Infant. Clinics in Perinatology, 40, 679-688. https://doi.org/10.1016/j.clp.2013.07.007

[30] Watchko, J.F. (2006) Hyperbilirubinemia and Bilirubin Toxicity in the Late Preterm Infant. Clinics in Perinatology, 33, 839-852.

https://doi.org/10.1016/j.clp.2006.09.002

[31] Gaton, D.D., Gold, J., Axer-Siegel, R., Wielunsky, E., Naor, N. and Nissenkorn, I. (1991) Evaluation of Bilirubin as Possible Protective Factor in the Prevention of Retinopathy of Prematurity. British Journal of Ophthalmology, 75, 532-534. https://doi.org/10.1136/bjo.75.9.532

[32] Milner, J.D., Aly, H.Z., Ward, L.B. and El-Mohandes, A. (2003) Does Elevated Peak Bilirubin Protect from Retinopathy of Prematurity in Very Low Birth Weight Infants. Journal of Perinatology, 23, 208-211. https://doi.org/10.1038/sj.jp.7210887

[33] Fauchère, J.C., Meier-Gibbons, F.E., Koerner, F. and Bossi, E. (1994) Retinopathy of Prematurity and Bilirubinno Clinical Evidence for a Beneficial Role of Bilirubin as a Physiological Anti-Oxidant. European Journal of Pediatrics, 153, 358-362. https://doi.org/10.1007/BF01956419

[34] Ochiai, M., Matsushita, Y., Inoue, H., Kusuda, T., Kang, D., Ichihara, K., et al. (2016) Blood Reference Intervals for Preterm Low-Birth-Weight Infants: A Multicenter Cohort Study in Japan. PLoS ONE, 11, e0161439.

https://doi.org/10.1371/journal.pone.0161439 https://www.ncbi.nlm.nih.gov/pubmed/27552225

[35] Bateman, D.A., Thomas, W., Parravicini, E., Polesana, E., Locatelli, C. and Lorenz, J.M. (2015) Serum Creatinine Concentration in Very-Low-Birth-Weight Infants from Birth to 34 - 36 wk Postmenstrual Age. Pediatric Research, 77, 696-702. https://www.ncbi.nlm.nih.gov/pubmed/25675426

[36] Black, M.J., Sutherland, M.R., Gubhaju, L., Kent, A.L., Dahlstrom, J.E. and Moore, L. (2013) When Birth Comes Early: Effects on Nephrogenesis. Nephrology, 18, 180-182. https://doi.org/10.1111/nep.12028

[37] Gubhaju, L., Sutherland, M.R., Yoder, B.A., Zulli, A., Bertram, J.F. and Black, M.J. (2009) Is Nephrogenesis Affected by Preterm Birth? Studies in a Non-Human Primate Model. American Journal of Physiology-Renal Physiology, 297, F1668-F1677. http://ajprenal.physiology.org/cgi/doi/10.1152/ajprenal.00163.2009

[38] Kushiyama, A. (2014) Linking Uric Acid Metabolism to Diabetic Complications. World Journal of Diabetes, 5, 787-795. https://doi.org/10.4239/wjd.v5.i6.787 http://www.wjgnet.com/1948-9358/full/v5/i6/787.htm

[39] Xia, J.F., Wang, Z.H. and Zhang, F.F. (2014) Association between Related Purine Metabolites and Diabetic Retinopathy in Type 2 Diabetic Patients. International 
Journal of Endocrinology, 2014, Article ID: 651050.

[40] Navin, S., Krishnamurthy, N., Ashakiran, S. and Dayanand, C.D. (2013) The Association of Hypomagnesaemia, High Normal Uricaemia and Dyslipidaemia in the Patients with Diabetic Retinopathy. Journal of Clinical and Diagnostic Research, 7, 1852-1854. 